\title{
PROPOSTA DE INOVAÇÃO NO ENSINO JURÍDICO: PROJETO LAWBORATORY. UMA IDEIA DE INTEGRAÇÃO DA PESQUISA COM O \\ MERCADO
}

Éderson Garin Porto
Fabiano Koff Coulon

Resumo: O Lawboratory surge da combinação das expressões inglesas "law" que significa Direito e "laboratory" que expressa o vocábulo laboratório. Como as universidades devem assumir um protagonismo do desenvolvimento econômico e tecnológico, os cursos jurídicos não podem e não devem se posicionar como meros caudatários das revoluções tecnológicas que estão surgindo. É da percepção de que a sala de aula e sobretudo a universidade deve servir de laboratório para a experimentação que se propõe criar um espaço de inovação para a prática do Direito, visando a aproximar o ensino e a pesquisa jurídica do mercado.

Palavras-chave: Ensino Jurídico; Inovação; Startup; Interação Empresa-Universidade; Hélice Tríplice.

\section{PROPOSAL FOR INNOVATION IN LEGAL EDUCATION: LAWBORATORY}

\section{PROJECT. AN IDEA OF LEGAL RESEARCH INTEGRATED WITH THE MARKET}

Abstract: Lawboratory comes from the combination of the English expressions "law" and "laboratory". As universities must assume a leading role in economic and technological development, law school can not and should not be regarded as mere caudates of the emerging technological revolutions. It is the perception that the classroom and especially the university should serve as a laboratory for experimentation that aims to create a space of innovation for the practice of Law, aiming at bringing education and legal research closer to the market.

Keywords: Legal Education; Innovation; Startup; Firm-University Integration; Triple Helix.

\footnotetext{
${ }^{1}$ Visiting Scholar UC Berkeley School of Law. Doutor em Direito pela Universidade Federal do Rio Grande do Sul (UFRGS). Mestre em Direito pela UFRGS. Bacharel em Direito pela Pontifícia Universidade Católica do Rio Grande do Sul (PUCRS). Professor do Mestrado Profissional da Unisinos. Professor de Direito Tributário na graduação e especialização na Universidade do Vale do Rio dos Sinos (UNISINOS). Coordenador do LLM em Tributação da Empresa e dos Negócios (UNISINOS). Coordenador do curso de especialização Direito e Gestão Tributária (UNISINOS). Fundador do Núcleo de Excelência LAWboratory (UNISINOS). Membro colaborador da Fundação Escola Superior de Direito Tributário (FESDT). Professor colaborador da Escola Superior da Advocacia - ESA OAB/RS. Membro da Comissão Especial de Direito Tributário da OAB/RS. Membro da Comissão de Sociedade de Advogados da OAB/RS. Advogado.

${ }^{2}$ Possui Graduação (1993), Mestrado (2007) e Doutorado (2013) em Direito pela Universidade Federal do Rio Grande do Sul (UFRGS). Professor do Mestrado Profissional em Direito da Empresa e dos Negócios e dos cursos de graduação em Direito e Relações Internacionais da Universidade do Vale do Rio dos Sinos (UNISINOS). Advogado atuante nas áreas do direito civil e empresarial, sócio de Coulon, Dresch e Masina Advogados, com sede em Porto Alegre/RS.
} 


\section{INTRODUÇÃO}

A experiência dos autores do ensaio estimulou a proposição de uma nova prática docente com a apresentação de um projeto pedagógico de integração faculdade de Direito com o mercado. Partindo da premissa de que o ensino jurídico enfrenta uma encruzilhada de esgotamento do modelo de ensino, assim como na missão institucional das escolas de Direito.

O presente estudo se propõe a apresentar a evolução do ensino jurídico explicando as razões da repetição de um único modelo de ensino que beira o esgotamento. Busca-se explicar porque um modelo esgotado se replica em todo o país e se reflete no marco regulatório do Ministério da Educação. O estado da arte no ensino jurídico explica a reprodução de práticas conhecidas e, ao mesmo tempo, justifica porque se deve pensar em práticas inovadoras.

No estudo se apresenta as vantagens da interação entre universidade e empresa e questionar os motivos que impedem do ensino jurídico de aproveitar uma interação mais intensa entre as universidades $\mathrm{e} \quad \mathrm{o}$ mercado.

Ao final, o artigo apresenta o projeto Lawboratory, explicando no que consiste e quais são os desafios a serem enfrentados. O problema apresentado consiste na formulação de uma prática pedagógica inovadora capaz de melhor o ensino jurídico e criar sinergia entre universidade e empresa. As hipóteses de pesquisa indicam que o projeto é capaz de promover melhor interação entre empresa e universidade e a proposta é capaz de gerar inovação no ensino jurídico. A pesquisa utiliza revisão bibliográfica de estudos realizados sobre a temática proposta e da discussão proposta pelos pesquisadores, pretende-se apresentar as proposições do projeto que está

sendo

desenvolvido.

\section{A TRADIÇÃO DO ENSINO JURÍDICO BRASILEIRO}

O ensino jurídico brasileiro enfrenta uma encruzilhada: reduzir a oferta dos cursos ou qualificar os cursos já existentes? Se o movimento de ampliação da oferta do ensino universitário no Brasil proporcionou que mais estudantes tivessem oportunidade de ingressar na universidade, por outro lado, a ampliação da oferta não foi acompanhada de uma avaliação criteriosa para a abertura de novos cursos, nem se observou uma atuação firme das instituições responsáveis pelo controle da qualidade dos cursos (MEDINA, 2006).

No plano do ensino jurídico, a proliferação dos cursos foi praticamente descontrolada, criando um universo de instituições que oferecem serviços educacionais de péssima qualidade 
e outras que replicam o mesmo modelo de ensino há décadas. O ensino jurídico não tem se revelado apto a preparar o acadêmico para o mercado profissional altamente competitivo, assim como não tem se revelado apto a contribuir para um desenvolvimento econômico importante com a qualificação das instituições e melhora do sistema jurídico pátrio. De um modo geral, os cursos jurídicos têm capacitado o egresso para o litígio, ensinando-lhe por sucessivos semestres competências e habilidades para o ajuizamento de demandas e a criação de estratégias processuais. Não poderia esperar que o profissional, depois de concluída a sua graduação, pense em algo diverso daquilo que foi capacitado. Em poucas palavras, os cursos de um modo geral, preparam o profissional para o litígio e não oferecem outras alternativas para o exercício da profissão. Este é o ponto central da presente investigação e algo que se pretende questionar.

\subsection{O MOVIMENTO DE CRIAÇÃO DO ENSINO JURÍDICO NO BRASIL}

O modelo de universidade brasileira é inegavelmente inspirado e estruturado a partir do modelo de universidade portuguesa, haja vista a colonização lusitana e a presença da Coroa portuguesa no país durante muitos anos (OLIVEIRA, 2002). Durante os primeiros anos da colonização portuguesa, os brasileiros que desejavam ter acesso ao ensino universitário deveriam viajar para Portugal, a fim de estudar na secular universidade de Coimbra ou na Faculdade de

Lisboa.

O ensino jurídico europeu, de um modo geral, estava calcado no estudo do "Corpus Iuris Civilis" que havia sido redescoberto e compilado por obra do imperador Justiniano no século VI (SOUSA, 2012). Além disso o estudo jurídico das universidades medievais estava ao encargo de instituições da igreja católica que desenvolveu o "Corpus Iuris Canonici”. Não é por acaso que o estudo e a interpretação do direito é uma tarefa exegese, hermenêutica. Os expoentes do pensamento jurídico são hábeis intérpretes da legislação, merecendo destaque a Escola dos Glosadores (1050-1130) surgida em Bolonha, seguida pela Escola dos PósGlosadores (Séculos XII-XV) que criaram o mos italicus. Na sequência, a Alemanha lega a Escola Pandectística, cujos maiores expoentes foram Puchta (1798-1846), Windscheid (18171892) Jhering (1818-1892) E Dernburg (1829-1907). A evolução do pensamento jurídico pode ser recontada a partir da evolução de certas escolas do pensamento jurídico que invariavelmente propunham uma forma própria de interpretação dos textos jurídicos. Tomando este contexto histórico, afigura-se claro porque o ensino jurídico desenvolveu-se no estudo e interpretação de textos

jurídicos

em

essência. 
No Brasil, o ensino jurídico desembarca de Portugal impregnado da tradição de ensino focado no estudo dos textos legais, compilação e glosa das obras codificatórias até então desenvolvidas na Europa. Consta que o primeiro estatuto a regulamentar o ensino jurídico no Brasil propunha um ensino focado no estudo da doutrina e da jurisprudência com o propósito de formar profissionais que tanto a jovem nação carecia (CUNHA e LEITE, 1996).

Até 1828 os Brasileiros formados em Direito eram egressos da Faculdade de Direito de Coimbra em sua imensa maioria. A partir de 11 de agosto de 1827, o Imperador Dom Pedro I editou a lei que viria a autorizar o funcionamento das duas primeiras faculdades de Direito no país (São Paulo e Olinda). Para Antonio Carlos Wolkmer chama a atenção das características exigidas pelo regulamento ao professor do ensino jurídico, chamado "lentes". Para a legislação valorizava-se o que Volkmer chamou de "intelectualismo alienígeno, inspirados em princípios advindos da cultura inglesa, francesa ou alemã" (WOLKMER, 2001).

O resgate do início do ensino jurídico no país evidencia que, em essência, os cursos de Direito pouco mudaram. Fica claro que desde a fundação da Faculdade de Direito do Largo do São Francisco até os mais recentes cursos jurídicos, a formação do bacharel é centrada na leitura, compreensão e interpretação de textos jurídicos com foco no litígio.

\subsection{O ESTÁGIO ATUAL DO ENSINO JURÍDICO NO BRASIL}

Pode-se afirmar que desde a promulgação da Constituição de 1988, o Brasil experimentou uma profusão de direitos assegurados no texto constitucional, o que demandou uma intensa renovação dos cursos jurídicos, assim como se observou um acréscimo acentuado de demandas no âmbito do Poder Judiciário. Naquele período, a Ordem dos Advogados do Brasil (OAB) desempenhava papel de destaque na avaliação dos cursos, possuindo desde 1972, a Resolução CFE 03/72 que dispunha sobre os critérios de avaliação dos cursos jurídicos.

O Estado passa a assumir papel protagonista com a edição da Lei de Diretrizes e Bases da Educação (Lei n ${ }^{\circ}$ 9.394/96) que instituiu um sistema de avaliação, cujo maior instrumento é o Exame Nacional de Cursos. O Ministério da Educação havia editado uma Portaria n ${ }^{\circ}$ 1.886/94 que passou a exigir que todos os cursos possuíssem um "Núcleo de Prática Jurídica".

Muito embora a OAB tenha se empenhado em avaliar e participar das atividades de ensino desenvolvidas pelas instituições, assim como não se pode deixar de reconhecer a importância das avaliações realizadas pelo Ministério da Educação, a verdade é que o ensino jurídico no país vem se repetindo desde a autorização para funcionar do primeiro curso em 
1828. A transformação passa da mudança radical sobre a estrutura de curso, focando a interdisciplinariedade, como destaca Paulo Luiz Neto Lôbo quando destaca que a formação do bacharel deve ser pautada pelo enlace:

\begin{abstract}
"com matérias que contribuem para a formação do profissional de Direito, notadamente estimuladoras da reflexão crítica e da atuação políticoinstitucional, que a sociedade cada vez mais dele reclama. Assim, a interessante abertura para as Ciências Sociais, Humanas, Políticas, para a Filosofia, incluindo as perspectivas lógica e ética, para a Psicologia, para a Informática, para a Ciência da Linguagem. [...]" (LÔBO, 1996).
\end{abstract}

Assim, o curso jurídico, para desempenhar com êxito a sua missão institucional, deve observar o que Paulo Luiz Neto Lôbo chamou de tríplice função: a) formação fundamental e sócio-política, que forneça ao aluno uma sólida base humanística e de capacitação crítica; b) formação técnico-jurídica, que o capacite ao exercício competente de sua profissão reconhecendo que as disciplinas dogmáticas admitem espaço à reflexão crítica; c) formação prática, oferecendo-lhes os meios para aplicar os conhecimentos obtidos (LÔBO, 1996).

As diretrizes curriculares do curso de graduação em Direito estão definidas pelo Conselho Nacional de Educação através da Resolução $n^{\circ} 9$ de 2004 que dispõe sobre os elementos básicos do projeto pedagógico. Vale transcrever o $\operatorname{artigo} 4^{\circ}$ da Resolução $n^{\circ} 9$ :

Art. $4^{\circ}$. O curso de graduação em Direito deverá possibilitar a formação profissional

que revele, pelo menos, as seguintes habilidades e competências: I - leitura, compreensão e elaboração de textos, atos e documentos jurídicos ou

normativos, com a devida utilização das normas técnico-jurídicas; II - interpretação e aplicação do Direito; III - pesquisa e utilização da legislação, da jurisprudência, da doutrina e de outras

fontes do Direito; IV - adequada atuação técnico-jurídica, em diferentes instâncias, administrativas

ou judiciais, com a devida utilização de processos, atos e procedimentos; V - correta utilização da terminologia jurídica ou da Ciência do Direito; VI - utilização de raciocínio jurídico, de argumentação, de persuasão e de reflexão

crítica;

VII - julgamento e tomada de decisões; e, VIII - domínio de tecnologias e métodos para permanente compreensão e aplicação do Direito. (BRASIL, 2004).

Nota-se que a regulamentação do curso continua orientando a formar o profissional vocacionado a compreensão e interpretação de textos com foco na resolução de conflitos. Esse 
estágio atual da evolução dos cursos jurídicos no país criou um enorme contingente de egressos aptos para o trabalho forense, focados no litígio e sem capacidade de proporcionar à sociedade alternativas viáveis para a construção de uma sociedade mais próspera. É pensando na formação de um profissional mais atualizado para os desafios atuais e capacitado para gerar valor para a sociedade que se pretendeu apresentar uma nova proposta pedagógica.

\section{A NECESSÁRIA INTEGRAÇÃO ENTRE EMPRESA E UNIVERSIDADE}

Os modelos de relação entre empresa e universidade, ou "relação U-E" (DANIGNO, 2003) têm recebido especial atenção por parte da comunidade científica, com a identificação de suas principais conformações e discussão de resultados ocupando um lugar proeminente entre as análises empreendidas.

Nessa seção busca-se apresentar a forma como esses modelos e sua evolução foram apresentados, principalmente seu desembocar na noção de "Hélice Tripla", conforme esboçada em Etzkowitz e Leydesdorff (2000), bem como seus resultados aparentes, segundo a literatura.

\subsection{OS MODELOS DE INTEGRAÇÃO E AS VANTAGENS ALCANÇADAS}

Os modelos de relação U-E foram propriamente identificados por Etzkowitz e Leydesdorff (2000) como tendo se sucedido no tempo de modo a representar a forma como se entende e efetiva as relações entre os três atores (daí "hélice tríplice" ou "tripla") envolvidos na produção de sistemas de inovação, sendo estes: a indústria, a academia e o estado.

$\mathrm{Na}$ visão dos autores, historicamente observou-se uma primeira conformação dessa relação, denominada Hélice Tríplice I, na qual o estado-nação abrange e direciona o âmbito da relação U-E, comandando os esforços dos demais atores. Tal modelo teria sido, em sua versão mais "forte", observado na União Soviética e seus estados-satélites durante a experiência comunista havida na Europa oriental durante a Guerra Fria. Segue abaixo uma representação gráfica do modelo Hélice Tríplice I: 


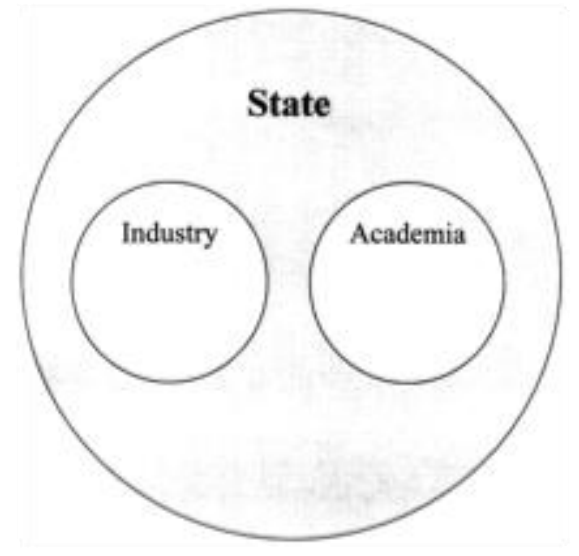

Fonte: Etzkowitz e Leydesdorff (2000).

O segundo modelo de relacionamento apresenta cada um dos atores circunscrito à sua própria esfera de atribuições, as quais se apresentam sem zonas de intersecção, com cada qual relacionando-se com as demais sem subordinação, razão pela qual tal modelo, denominado Hélice Tríplice II, é referido como próprio de uma política de laissez-faire, provavelmente em contraposição ao modelo Hélice Tripla I. É graficamente representado da seguinte forma:

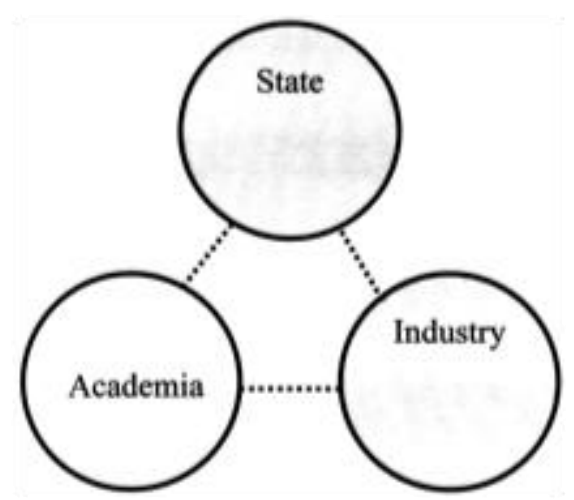

Fonte: Etzkowitz e Leydesdorff (2000).

Por fim, no terceiro modelo, denominado Hélice Tríplice III, as distintas esferas apresentam zonas de interseção, nas quais concentram-se estruturas híbridas e alianças estratégicas, com o estado assumindo uma função de impulsionamento, mas não de controle da atividade de inovação. Segue representação gráfica elaborada pelos autores: 


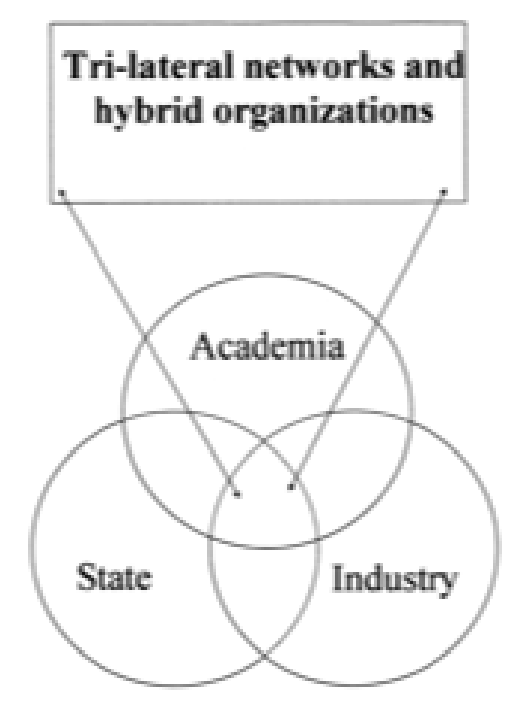

Fonte: Etzkowitz e Leydesdorff (2000).

Segundo Etzkowitz e Leydesdorff (2000), o modelo Hélice Tríplice III é o que tem sido mais frequentemente utilizado na criação de ambientes de estímulo à inovação na maioria dos países $^{3}$, dentre estes incluindo-se o Brasil, no qual tal modelo tem sido objeto de atenção especial por parte da literatura especializada (ver Dagnino, 2003).

Caracterizados os principais modelos de interação U-E baseados no conceito de Hélice Tríplice, incumbe referir suas principais vantagens e dificuldades já identificadas. Schaeffer, Ruffoni e Puffal, (2015), ao revisar a literatura existente sobre o tema em busca de síntese acerca das razões, dos benefícios e das dificuldades encontrados no relacionamento entre universidade e meio empresarial, chegaram ao resultado representado no seguinte quadro esquemático:

\footnotetext{
${ }^{3}$ Nas palavras dos autores: "In one form or another, most countries and re-gions are presently trying to attain some form of Triple Helix III. The common objective is to realize an innovative environment consisting of university spin-off firms, tri-lateral initiatives for knowledge- based economic development, and strategic alliances among firms Žlarge and small, operating in different areas, and with different levels of technology., gov- ernment laboratories, and academic research groups." (ETZKOWITZ; LEYDESDORFF, 2000, p. 112).
} 
QUADRO 1

Sintese da pesquisa

\begin{tabular}{|c|c|c|c|}
\hline Conceitas & Definiçôes & $\begin{array}{l}\text { Categorias de } \\
\text { variáveis (1) }\end{array}$ & Autores \\
\hline \multirow{4}{*}{ Razōes } & \multirow{4}{*}{$\begin{array}{l}\text { Inexistência } \\
\text { de capacidades } \\
\text { internas } \\
\text { suficientes para } \\
\text { a concrecizaçióo } \\
\text { da estracégia } \\
\text { organizacional } \\
\text { que fundamenta } \\
\text { a busca por fontes } \\
\text { externas }\end{array}$} & $\begin{array}{l}\text { Conhecimento e } \\
\text { tecnologia }\end{array}$ & $\begin{array}{c}\text { Prager e Omenn (1980), } \\
\text { Bonaccorsi e Piccaluga (1994), } \\
\text { Segatto (1996), } \\
\text { Segatro-Mendes e Sbragia (2002), } \\
\text { Arza (2010), D'Este e Perkmann } \\
\text { (2011), } \\
\text { Porto ec al. (2011), Shima e } \\
\text { Scatolin (2011) }\end{array}$ \\
\hline & & Acesso a recursos & $\begin{array}{c}\text { Prager c Omenn (1980), } \\
\text { Bonaccorsi c Piccaluga (1994), } \\
\text { Arza (2010), } \\
\text { Porto et al. (2011), Shima e } \\
\text { Scatolin (2011) }\end{array}$ \\
\hline & & Industrial & $\begin{array}{c}\text { Prager e Omenn (1980), } \\
\text { Bonaccorsi e Piccaluga (1994), } \\
\text { Segaro-Mendes e Sbragia (2002), } \\
\text { D'Este c Perkmann (2011), } \\
\text { Porto et al. (201 1), Shima e } \\
\text { Scatolin (2011) }\end{array}$ \\
\hline & & Institucional & $\begin{array}{c}\text { Segatto (1996), D'Este e Perkmann } \\
\text { (2011) }\end{array}$ \\
\hline
\end{tabular}

Fonte: Schaeffer, Ruffoni e Puffal, (2015). 


\begin{tabular}{|c|c|c|c|}
\hline \multicolumn{4}{|c|}{$\begin{array}{c}\text { QUADRO } 1 \\
\text { Sintese da pesquisa }\end{array}$} \\
\hline Conceitos & Definiçōes & $\begin{array}{l}\text { Categorias de } \\
\text { variáveis (1) }\end{array}$ & Autores \\
\hline \multirow{4}{*}{ Beneficios } & \multirow{4}{*}{$\begin{array}{l}\text { Para as } \\
\text { universidades, } \\
\text { os benefficios } \\
\text { podem ser de } \\
\text { caráter intelectual } \\
\text { ou cconômico, } \\
\text { enquanto para as } \\
\text { empresas podem } \\
\text { ser de produçấo } \\
\text { ou inovaçîa }\end{array}$} & Insticucional & $\begin{array}{l}\text { Feller, Ailes e Roessner (2002), } \\
\text { Rapini er al. (2009), Fernandes et } \\
\text { al. (2010) }\end{array}$ \\
\hline & & Produtos/processos & $\begin{array}{l}\text { Dutrénit e Arza (2010), Fernandes } \\
\text { et al. }(2010)\end{array}$ \\
\hline & & Projetos & $\begin{array}{l}\text { Bonaccorsi e Piccaluga (1994), } \\
\text { Meyer-Krahmer e Schmoch } \\
\text { (1998), Feller, Ailes e Roessner } \\
\text { (2002), Rapini er al. (2009), } \\
\text { Dutrénir e Arza (2010), Fernandes } \\
\text { er al. (2010) }\end{array}$ \\
\hline & & $\begin{array}{l}\text { Recursos } \\
\text { financeiros }\end{array}$ & Meyer-Krahmer e Schmoch (1998) \\
\hline \multirow{5}{*}{ Dificuldades } & \multirow{5}{*}{$\begin{array}{l}\text { Barreiras que } \\
\text { dificultam e } \\
\text { restringem o } \\
\text { processo de } \\
\text { cooperaçio entre } \\
\text { universidades e } \\
\text { empresas }\end{array}$} & Insticucional & $\begin{array}{c}\text { Segatco (1996), Reis (1998), } \\
\text { Meyer-Krahmer e Schmoch } \\
\text { (1998), Feller, Ailes e Roessner } \\
\text { (2002), Arvanitis, Kubli e Woerter } \\
\text { (2008), Shima e Scawlin (2011), } \\
\text { Tartari e Breschi (2012), Freitas, } \\
\text { Marques e Silva (2013) }\end{array}$ \\
\hline & & $\begin{array}{l}\text { Independência } \\
\text { cientffica }\end{array}$ & Tartari e Breschi (2012) \\
\hline & & Interesses & $\begin{array}{l}\text { Segatwo (1996), Reis (1998), } \\
\text { Meyer-Krahmer e Schmoch } \\
\text { (1998), Shima e Scatolin (2011), } \\
\text { Freitas, Marques e Silva (2013) }\end{array}$ \\
\hline & & Recursos humanos & $\begin{array}{l}\text { Segatto (1996), Reis (1998), } \\
\text { Shima e Scatolin (2011) }\end{array}$ \\
\hline & & Geografia & Segarto $(1996)$ \\
\hline
\end{tabular}

Fonte: Schaeffer, Ruffoni e Puffal, (2015).

Pode-se perceber na pesquisa empreendida pelos autores que os benefícios mais comumente esperados da relação U-E são: para a universidade, principalmente de ordem intelectual (como a busca de inspiração para novas pesquisas, formação de recursos humanos, elaboração de teses e dissertações etc.) e econômica; para a empresa, seriam, a curto prazo, visando a produção (tais como a realização de testes de produtos e soluções para processos de produção), e, a longo prazo, benefícios relacionados à inovação. Falando mais propriamente sobre o contexto Latino-Americano, afirmam: 
Por fim, os benefícios apresentam-se como intelectuais ou econômicos, no que compete à percepção das universidades, e em produtivos ou de inovação, conforme as empresas. Não obstante, se averigua, nos estudos que focaram países da América Latina, a predominância dos benefícios intelectuais para as universidades e dos benefícios em produção para as empresas, os quais se encontram relacionados ao curto prazo. (SCHAEFFER; RUFFONI; PUFFAL, 2015, p. 111).

Já no que diz respeito às dificuldades sentidas por universidades e empresas em seu relacionamento, são mais comumente apontadas pela literatura as seguintes: no âmbito das universidades, principalmente, as incertezas em relação aos projetos, a burocracia em nível elevado, aos direitos sobre patentes e resultados de pesquisas, as diferenças de conhecimento entre os agentes envolvidos, a orientação das empresas para o curto prazo, as restrições às publicações, a perda de autonomia no processo de investigação, dentre outras; já no que diz respeito às empresas, os principais entraves referidos são a localização geográfica da universidade, a burocracia universitária, a duração longeva dos projetos, as diferenças nos níveis de conhecimento entre os agentes, dentre outras (SCHAEFFER; RUFFONI; PUFFAL, 2015, p. 111).

Identificados assim os principais modelos através dos quais se costuma conceber a interação entre universidade e meio empresarial, sem olvidar a integração do estado no conceito de Hélice Tripla, bem como os benefícios esperados pelos agentes e as dificuldades sentidas nos processos de inovação, incumbe agora, dentro da proposta da presente pesquisa, abordar a questão das dificuldades sentidas para a integração a partir da perspectiva das limitações do ensino jurídico tradicional.

\subsection{AS DIFICULDADES PARA INTEGRAÇÃO NO ÂMBITO DO ENSINO} JURÍDICO

O ensino jurídico no Brasil, com escassas exceções, ainda possui características excessivamente tradicionais que contrastam com o modelo de integração entre universidade e empresa no qual se devam potencializar benefícios mútuos e implementar sinergias.

A começar pelos currículos existentes, que, em sua imensa maioria, privilegiam a produção e discussão quase exclusiva do conhecimento teórico e nos quais o fenômeno empresarial é enfocado pelas lentes da legislação, em perspectiva na qual a empresa é usualmente vista como um conceito jurídico apartado de suas dimensões econômicas e 
organizacionais, em um mundo em que o direito, a economia e a teoria da administração são esferas de conhecimento praticamente excludentes.

Adiciona-se às dificuldades intrínsecas a tal modelo a metodologia de ensino aplicada nos espaços universitários, a qual ainda é, na maior parte, formada por aulas expositivas, em modelo baseado na figura de autoridade do professor e nas quais se pretende transmitir o conhecimento em percurso praticamente unilateral, sobretudo quando não raro se desestimula a intervenção crítica do aluno, por vezes interpretada como desafio a essa autoridade.

A aplicação dos conteúdos transmitidos e o potencial de conhecimento que se possa daí obter é feito frequentemente fora da universidade, através dos estágios em entidades privadas e órgãos públicos que apenas alguns alunos conseguem alcançar, frequentemente mediante o emprego de sua rede privada de relacionamentos. Ou então, quando empreendida dentro do campus universitário, tal experiência, embora rica em possibilidades de aprendizado, frequentemente envolve dimensões que não guardam relação direta com o ambiente empresarial, apresentando-se, portanto, praticamente irrelevante no que diz respeito à relação U-E enquanto produtora de conhecimento e inovação também para o ambiente jurídico.

Mesmo em instituições de ensino superior nas quais se encontra desenvolvido um ambiente de inovação em que se congregam os atores da Hélice Tríplice, principalmente universidade e empresa, tal quadro normalmente não se altera, sendo escassa a participação de professores, pesquisadores ou acadêmicos do curso de direito em projetos gestados nos sistemas de inovação universitários tais como incubadoras, parques tecnológicos, etc.

A superação do modelo baseado no ensino quase exclusivamente teórico e afastado de áreas do conhecimento como economia, administração, contábeis, e a criação de oportunidades para que a comunidade jurídica da academia possa colaborar com as empresas que buscam na universidade a produção de benefícios em comum através da geração de conhecimento e inovação parecem ser os desafios mais evidentes para uma maior integração dos acadêmicos do direito na relação U-E.

Nesse contexto, como tentativa de enfrentamento desses desafios, passa-se a apresentar o projeto Lawboratory, empreendido no contexto do Sistema de Inovação existente na Universidade do Vale do Rio dos Sinos - UNISINOS. 


\section{O PROJETO LAWBORATORY}

O projeto Lawboratory surge da combinação das expressões inglesas law que significa Direito e laboratory que expressa o vocábulo laboratório. Como as universidades devem assumir um protagonismo do desenvolvimento econômico e tecnológico (AUDY, 2017), os cursos jurídicos não podem e não devem se posicionar como meros caudatários das revoluções tecnológicas que estão surgindo. É da percepção que a sala de aula e sobretudo a universidade deve servir de laboratório para a experimentação que se imaginou adequado criar um espaço de inovação para a prática do Direito, visando a aproximar o ensino e a pesquisa jurídica do mercado.

Assim o projeto pode ser resumido como um espaço de estudo e aplicação de conhecimentos e técnicas modernos com a pretensão de solucionar problemas concretos enfrentados pelo ecossistema de inovação. Pretende-se aproximar as linhas de pesquisa dos pesquisadores da Escola de Direito com as demandas do mercado no sentido de oferecer soluções jurídicas que resolvam problemas concretos e atuais.

\subsection{A IDEIA DE PROMOVER A INTEGRAÇÃO ENTRE A PESQUISA E O} MERCADO

O Projeto pretende criar um "hub" de conexão entre os melhores profissionais e pesquisadores com o mercado, oferecendo dentro da universidade uma assessoria jurídica de excelência e tornar o núcleo em referência em desenvolvimento e soluções para projetos inovadores incubados dentro universidade.

Inspirando-se na experiência das universidades norte-americanas, que há muitos anos aproveitam a sinergia da capacidade técnica de seus acadêmicos e egressos, busca-se oferecer uma opção para as empresas incubadas resolver questões jurídicas dentro da própria universidade, tendo em mente que a contratação de profissionais gabaritados no mercado geralmente representa um custo elevado que as empresas em estágio inicial não apresentam capacidade de pagar. Busca-se, ainda, institucionalizar um espaço de capacitação prática aos alunos, oferecendo aos alunos dos cursos de graduação em Direito e do Mestrado Profissional da Escola de Direito a oportunidade de experimentação e inserção do futuro profissional no ambiente de inovação tecnológica.

Pode-se dizer que o objetivo principal do projeto é oferecer apoio técnico-jurídico para 
os negócios a serem incubados no parque tecnológico da universidade, oferecendo aos projetos assessoria jurídica e, ao mesmo tempo, oportunizando aos alunos experiência profissional diversificada.

O projeto aprovado no âmbito dos Núcleos de Excelência instituído pela universidade busca se consolidar como um polo de inovação jurídica, posicionando-se na vanguarda de soluções para os ambientes de inovação e sobretudo demonstrar a oportunidade de atuação do profissional do Direito para além do cotidiano forense.

As soluções visam ofertar assessoria jurídica de forma especializada na linha exclusivamente consultiva, aliando a expertise dos profissionais envolvidas no projeto, cuja atuação no mercado da advocacia possui consolidação e renome de longa data. A assessoria jurídica não se limitará ao atendimento jurídico standard, possibilitando, também, aliar as informações advindas dos projetos de pesquisas em que os profissionais atuam, proporcionando novas possibilidades para as destinatárias da assessoria jurídica.

O grande foco do presente projeto é possibilitar o contato dos graduandos e mestrandos com área de inovação e tecnologia, oportunizando um espaço de prática e aprendizado diversa daquela já vivenciada nos núcleos de prática que são essencialmente forense. Nos núcleos de prática jurídica atuais, o acadêmico atende a comunidade de baixa renda em questões jurídicas tradicionais, resolvendo os conflitos preponderantemente com o ajuizamento de demandas.

A ideia central deste projeto já é amplamente realizada, com sucesso, em faculdades estrangeiras, em especial as norte-americanas, que adotam a prática de clinicas jurídicas no intuito de aproximar os estudantes de direito com a realidade da área empresarial que os espera após conclusão do curso.

A inspiração para o projeto teve origem no estágio pós-doutoral de um dos coordenadores do projeto, quando pesquisando na Universidade da Califórnia - Berkeley School of Law, conheceu o núcleo de apoio a Startups e empreendedores. O projeto visa inclusive intensificar a relação entre as duas universidades e colocar o ensino jurídico alinhado com as melhores práticas das universidades estrangeiras. 


\subsection{OS DESAFIOS DO PROJETO}

A proposta é imediatamente confundida com a criação de um escritório de advocacia modelo. O principal desafio dos fundadores do projeto é não permitir que a sociedade vislumbre a proposta pedagógica com a criação de um escritório de advocacia que esteja competindo ou disputando o mercado com outros profissionais capacitados para atuar no mercado.

É evidente que o foco é o atendimento remunerado de empresas em estágio inicial, no entanto, não se pretende tornar as empresas cativas do serviço oferecido, nem se pretende oferecer todas as soluções jurídicas que um escritório de advocacia "full service" se propõe a oferecer. Não se almeja criar no mercado a referência na oferta de serviços jurídicos tradicionais, mas sim na busca de soluções ainda não apresentadas pelo mercado e que a partir do lançamento do produto pelo Lawboratory poderá ser replicado e até mesmo copiado pelo mercado.

Como já referido, os cursos de Direito, por imposição da Resolução n 09/2004, devem dispor de núcleo de prática jurídica. Na universidade acolhedora do projeto não é diferente. Há um núcleo consolidado de prática jurídica, onde se presta auxílio jurídico a pessoas, residentes nas imediações da universidade, todos de baixa renda, ao mesmo tempo que confere aos estudantes de Direito a oportunidade de exercer a advocacia forense.

Apesar das semelhanças, o projeto em questão possui inúmeras diferenças entre o já existente núcleo de Prática Jurídica da instituição. A proposta apresentada visa preencher uma lacuna presente e possibilitar aos alunos, que possuem interesse em focar seus estudos na área empresarial, que possam desfrutar de um ambiente para desenvolver as habilidades teóricas que adquiriram durante

o curso.

Atualmente, o aluno que queira praticar os conhecimentos adquiridos na área empresarial, deverá fazê-lo principalmente fora da Universidade. Com a implementação do projeto, possibilitar-se-á que este aluno o faça dentro do ambiente acadêmico e sob a supervisão de profissionais amplamente qualificados.

Outro ponto a ser explorado é o potencial de autofinanciamento do projeto, pois o serviço será oferecido às Empresas instaladas no polo tecnológico da universidade de forma onerosa, fazendo com que a Instituição não precise realizar investimento para que o projeto seja implementado e mantido. Diferentemente dos núcleos de prática forense tradicionais que atendem famílias de baixa renda e, por óbvio, não remuneram os serviços, este projeto será financiado exclusivamente pelas interações da universidade com o mercado, sem qualquer 
subsídio

da

universidade.

\section{CONCLUSÕES}

O presente ensaio desenvolve a identificação de um problema grave na formação jurídica dos bacharéis em Direito: foca-se a formação de maneira excessiva no estudo da legislação e na resolução de litígios e esquece-se que a missão do Direito é muito maior e mais importante.

Os profissionais do Direito, além de capacitados em interpretar e aplicar a legislação, devem compreender o contexto econômico e social em que estão inseridos, tornando-se capazes de oferecer soluções para o desenvolvimento da sociedade de formas alternativas ao acionamento do Poder Judiciário. Não se pretende transformar o profissional do Direito, nem subverter o curso em sua essência. A proposta da investigação e, por decorrência, do projeto que embasa o estudo é oferecer alternativas e expandir as oportunidades.

A investigação identificou que historicamente o ensino jurídico na Europa continental e no Brasil, desde a independência, esteve focado no estudo da legislação e manuseio de técnicas interpretativas. No entanto, o problema suscitado parte da premissa que o método de ensino tradicional do Direito está chegando ao seu esgotamento, sem a capacidade de propiciar uma forma de adequada de transmissão de conhecimento aos acadêmicos que chegam a universidade oriundos de realidades distintas e que retornaram para atuar em uma sociedade totalmente distinta daquela em que o ensino jurídico desembarcou no Brasil.

A interação entre empresa e universidade, em que pese seja desejável e se revele capaz de gerar benefícios mútuos, tem tímida participação de professores, pesquisadores ou acadêmicos do curso de direito em projetos gestados nos sistemas de inovação universitários tais como incubadoras, parques tecnológicos, etc. A superação do modelo baseado no ensino quase exclusivamente teórico e afastado de áreas do conhecimento como economia, administração, contábeis, e a criação de oportunidades para que a comunidade jurídica da academia possa colaborar com as empresas que buscam na universidade a produção de benefícios em comum através da geração de conhecimento e inovação parecem ser os desafios mais evidentes para uma maior integração dos acadêmicos do direito na relação U-E.

É nesse cenário que surge o projeto Lawboratory, buscando aproximar universidade do mercado. Busca-se a criação de um conceito de prática pedagógica que permita que as pesquisas e conhecimento desenvolvido em sala de aula seja aplicado em casos práticos e a relevância da 
pesquisa seja validada pelo mercado. Significa dizer que tanto melhor e mais produtiva será a pesquisa desenvolvida quanto maior for o interesse do mercado em adquirir os serviços oferecidos pelo projeto.

\section{REFERÊNCIAS BIBLIOGRÁFICAS}

ANDREASSI, Tales. Estudo das relações entre indicadores de P\&D e indicadores de resultado empresarial em empresas brasileiras. 1999. Tese (Doutorado) — Faculdade de Economia, Administração e Contabilidade da Universidade de São Paulo, São Paulo.

AUDY, Jorge. A inovação, o desenvolvimento e o papel da Universidade. In: Estudos Avançados, print version ISSN 0103-4014, on-line version ISSN 1806-9592 Estud. Av. vol.31, $\mathrm{n}^{\circ}$ 90, São Paulo, May/Aug. 2017, disponível em http://dx.doi.org/10.1590/s010340142017.3190005 .

BLOEDON, Robert V.; STOKES, Deborah R. Making university/ industry collaborative research succeed. Research Technology Management, v.37, n.2, p.44-48, mar./abr. 1994.

BONACCORSI, A.; PICCALUGA, A. A theoretical framewok for the evoluation of university$\begin{array}{lllll}\text { industry relationships. } & \text { R\&D } & \text { Management, } & \text { v.24, } & \text { n.3, }\end{array}$

CHAIMOVICH, Hernan. Por uma relação mutuamente proveitosa entre universidade de pesquisa e empresas. Revista de Administração da USP (RAUSP), São Paulo, v.34, n.4, p.1822 ,

out./dez.

1999.

CUNHA, M.I.; LEITE, D. Decisões pedagógicas e estruturas de poder na universidade. Campinas:

Papirus,

1996.

DEZALAY, Ives; TRUBEK, David M.. A Reestruturação Global e o Direito. In.: FARIA, José Eduardo (org.). Direito e Globalização Econômica: Implicações e Perspectivas. $1^{\mathrm{a}}$ ed. São Paulo:

Malheiros,

2010.

LÔBO, Paulo Luiz Neto. O novo conteúdo mínimo dos cursos jurídicos. In: OAB/Ensino Jurídico. Novas Diretrizes Curriculares. Brasília: OAB, 1996.

LOPÉZ-MARTINEZ, R.E.; MEDELLÍN, E.; SCALON, A.P.; SOLLEIRO, J.L. Motivations and obstacles to university industry cooperation (UIC): a Mexican case. R\&D Management, v.24,

n.1,

p.17-31,

Jan.

1994.

MACLACHLAN, Alexander. Industrial expectations and the research universities. Research Technology Management, v.37, n.6, p.9-10, $\quad$ Nov./Dec. 1994.

MARCOVITCH, Jacques. A cooperação da universidade moderna com o setor empresarial. Revista de Administração da USP (RAUSP), São Paulo, v.34, n.4, p.13-17, out./dez. 1999. 
MEDINA, Paulo Roberto de Gouvêa. Ensino jurídico, literatura e ética. Brasília: OAB Editora,

OLIVEIRA, Terezinha. Origem e Memória das Universidades Medievais a preservação de uma instituição educacional. Disponível no www.scielo.br/pdf/vh/v23n37/v23n37a07.pdf. Consulta em 03/09/2018.

PLONSKI, Guilherme Ary. Prefácio a la cooperación empresa- universidad en Iberoámerica, In: PLONSKI, G.A. (Ed.) Cooperación empresa-universidade en Iberoámerica. São Paulo: $\begin{array}{llll}\text { Programa } & \text { CYTED, } & 1992 . & \text { p.VII-XIV. }\end{array}$ . Cooperação empresa-universidade na Ibero-América: estágio atual e perspectivas. In: SIMPÓSIO DE GESTÃO DA INOVAÇÃO TECNOLÓGICA, 17. Anais, São Paulo, $1994 . \quad$ p.361-376. - Cooperação empresa-universidade: antigos dilemas, novos desafios. Revista USP, São Paulo, v.25, p.32- 41, mar./maio 1995.

PORTO, Geciane Silveira. A decisão empresarial de desenvolvimento tecnológico por meio da cooperação empresa-universidade. 2000. Tese (Doutorado) - Faculdade de Economia, Administração e Contabilidade da Universidade de São Paulo, São Paulo. PRAGER, O.J.; OMENN, G.S. Research, inovation and university-industry linkages. Science, $\begin{array}{llll}\text { v. } 207, & \text { n.25, } & 1980 .\end{array}$

RIPPER FILHO, José Ellis. Universidade-empresa: a interação possível. Ciência Hoje, v.4, n.19, p.82-86, 1993.

ROSENBERG, Nathan; NELSON, Richard R. American universities and technical advance in industry. Research Policy, v.23, n.3, p.323-348, May 1994. SOUSA, Miguel Teixeira de. Introdução ao Direito. Coimbra: Almedina, 2012. WOLKMER, Antonio Carlos. Introdução ao Pensamento Jurídico Crítico. 3. ed. São Paulo: Saraiva, 2001. 